\title{
Avaliação microbiológica de Queijo do Marajó tipo creme, de leite de búfala, elaborado em queijarias da Ilha do Marajó, Pará
}

\begin{abstract}
Microbiological evaluation of Marajo Cheese cream type, buffalo milk, produced in dairies of
\end{abstract} Marajo Island, Pará

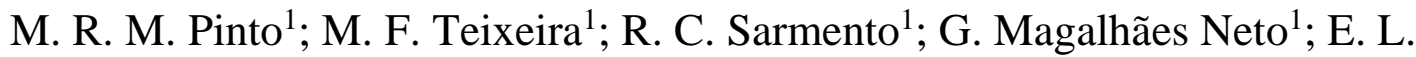
Figueiredo $^{2 *}$

${ }^{l}$ Graduandos do Curso de Tecnologia de Alimento, Universidade do Estado do Pará, Núcleo Universitário de Salvaterra, 68.860-000, Salvaterra-Pará,Brasil

${ }_{2}^{2}$ Docente do Curso de Tecnologia de Alimentos, Departamento de Tecnlogia de Alimentos, Universidade do Estado do Pará, 66.095-105, Belém-Pará, Brasil

*lane_figueiredo@yahoo.com.br

(Recebido em 01 abril de 2016; aceito em 15 de abril de 2016)

\begin{abstract}
O Queijo do Marajó, obtido a partir do leite de búfala, representa uma importante atividade econômica no Estado do Pará, em especial na Ilha do Marajó, no qual vigora a produção de forma artesanal. Este trabalho tem como objetivo avaliar a qualidade microbiológica do Queijo do Marajó, tipo creme, de leite de búfala, elaborados em duas queijarias localizadas na ilha do Marajó, Pará, a fim de verificar se os derivados encontram-se em condições microbiológicas e higiênico-sanitárias adequadas. Foram realizadas análises microbiológicas de Coliformes Totais, Coliformes Termotolerantes, Staphylococcus aureus, contagem padrão de bactérias aeróbias mesófilas, e contagem de fungos filamentosos e leveduras. Todas as análises seguiram a metodologia descrita na Instrução Normativa $\mathrm{n}^{\circ}$ 62, de 26 de Agosto de 2003, do Ministério da Agricultura, Pecuária e Abastecimento. As médias dos resultados microbiológicos mostraram que as amostras de queijo das duas queijarias avaliadas não apresentaram contaminação por nenhum dos micro-organismos analisados, estando assim de acordo com o Regulamento Técnico de Produção do Queijo do Marajó, Portaria no 418, de 04/03/2013. Diante dos resultados obtidos, pode-se verificar a importância de cuidados de higiene no processo de fabricação do derivado, e que o tratamento térmico utilizado nas etapas de elaboração, também contribuiu para garantir a qualidade do produto final.

Palavras-chave: Queijo do Marajó, búfala, Murrah
\end{abstract}

Cheese Marajó, obtained from buffalo milk, is an important economic activity in the State of Pará, especially in Marajó Island, where force production by hand. This study aims to evaluate the microbiological quality of Cheese Marajó, cream type, buffalo milk, drawn up in two dairies located in Marajó Island, Pará, in order to verify that the derivatives are in microbiological and hygienic conditions adequate sanitation. Microbiological analyzes were performed for Total Coliforms, Coliforms thermotolerant, Staphylococcus aureus, standard count mesophilic aerobic bacteria and fungi count filamentous and yeast. All analyzes followed the methodology described in Instruction No. 62, of August 26, 2003, the Ministry of Agriculture, Livestock and Supply. The means of microbiological results showed that samples of cheese from the two evaluated dairies were not contaminated by any of the analyzed micro-organisms and is in accordance with the Production Technical Regulation Cheese Marajó, Ordinance No. 418 of 04/03/2013. Based on these results, it can be seen the importance of hygiene in the secondary manufacturing process, and that the heat treatment used in the preparation stages, also contributed to ensure the quality of the final product.

Keywords: Cheese Marajó, buffalo, Murrah

\section{INTRODUÇÃO}

No Brasil, a produção artesanal de queijos ocorre desde o século XVIII e algumas técnicas de fabricação continuam preservadas. Esses queijos têm importância que não se limitam apenas às suas qualidades sensoriais, mas também desempenham um importante papel social, 
econômico e cultural [1]. Eles refletem a história e a tradição de quem os produz em um conhecimento passado de geração em geração [2].

O Queijo do Marajó é um produto artesanal típico da região da Ilha de Marajó, oriundo da produção familiar, de derivados do leite de búfala. É definido como "o produto elaborado artesanalmente na área geográfica do arquipélago do Marajó, conforme a tradição histórica e cultural da região, obtido pela fusão da massa coalhada, dessorada de leite de búfala e/ou leite de búfala misturado com leite bovino na proporção máxima de $40 \%$, lavada com água ou leite de búfala ou bovino, obtido por coagulação espontânea e adicionado de creme de leite ou manteiga" [3]. Apresenta textura macia, compacta e fechada, com pequenos poros, aroma agradável, de cor branca, sabor ligeiramente ácido e salgado [4, 5].

Pode ser elaborado por dois processos diferentes, diferenciando-o no tipo creme, quando o cozimento da massa é feito adicionando-se o creme obtido do desnate, com $50 \%$ de umidade e $22 \%$ de lipídeos; e o tipo manteiga, quando em seu cozimento é adicionada a manteiga propriamente dita, com $35 \%$ de umidade e $42 \%$ de lipídeos [6, 7].

Para a sua elaboração, o leite bubalino é inicialmente filtrado, seguido de seu desnate. O leite é transferido para um tanque, por um período de 24 horas, sob temperatura média de $26^{\circ} \mathrm{C}$, para a fermentação natural [8]. A massa resultante é colocada em sacos de nylon para dessora. É feita uma primeira lavagem com água, em tachos de aço inoxidável, e posteriormente a massa é levada ao aquecimento de $\pm 55{ }^{\circ} \mathrm{C}$. Ocorre a prensagem da massa, e posteriormente uma segunda lavagem com água. As lavagens têm como objetivo diminuir a acidez da mesma $\left(12^{\circ}\right.$ Dornic ou $\mathrm{pH} 5,2$ ). A massa é submetida ao $1^{\circ}$ cozimento, sob temperatura de $\pm 80{ }^{\circ} \mathrm{C}$. Em seguida ocorre nova dessora ( $2^{\mathrm{a}}$ prensagem). Adicionam-se, sobre a massa, $10 \%$ de leite desnatado, fresco, proporcional ao volume da massa inicial. Procede-se um segundo cozimento, $\mathrm{a} \pm 80^{\circ} \mathrm{C}$ por 15 minutos, e em seguida uma nova dessora ( $3^{\mathrm{a}}$ prensagem). Faz-se o resfriamento da massa, e posteriormente o corte e a moagem, até atingir aspecto de "esfarelamento". Sobre a massa esfarelada, são adicionados sorbato de potássio $( \pm 0,1 \%)$ e cloreto de sódio (de 1 a $2 \%$ ), proporcional ao volume da massa inicial, ambos autorizados pela Portaria $\mathrm{n}^{\circ} 418$ [3]. Na elaboração do queijo Tipo Creme, é adicionado o creme, e na elaboração do Tipo Manteiga, a manteiga. O creme e a manteiga, obtidos no desnate, são adicionados em pequenas proporções, até que a massa absorva todo o creme e a manteiga adicionados. Procede-se a mexedura, sob temperatura de $55^{\circ} \mathrm{C}$, por aproximadamente 30 minutos ( $3^{\circ}$ cozimento), até que o queijo atinja o "ponto", percebido quando se desprende do fundo do tacho. Ocorre o pré-resfriamento, em local arejado, e segue-se a enformagem dos produtos $[4,7]$.

Os municípios de Soure, Salvaterra e Cachoeira do Arari são os maiores centros produtores desse tipo de queijo no Pará, constituindo-se como um investimento atrativo para a economia local. Estima-se que existam cerca de 20 indústrias de porte médio, no Marajó, com capacidade para produção de $20 \mathrm{~kg}$ a $50 \mathrm{~kg}$ de queijo/dia. As indústrias caseiras, que produzem de $2 \mathrm{~kg}$ a 10 $\mathrm{kg}$ de queijo/dia, estão concentradas, principalmente, em Soure e Cachoeira do Arari. A maioria da produção de Queijo do Marajó é destinada a Belém [5].

É na qualidade do leite bubalino que reside a maior vantagem desse produto. É mais concentrado do que o leite bovino, apresentando, desde modo, menos água e mais matéria seca [8]. Seus valores de lipídeos, proteínas, lactose, sólidos totais, e resíduo mineral fixo, são de grande importância nutricional. Para indústria láctea seu aproveitamento é superior, com rendimento de $40 \%$ a mais do que o leite bovino para a elaboração de derivados. Por exemplo, para a elaboração de $1 \mathrm{~kg}$ de Queijo do Marajó, são necessários 12 litros de leite bovino, enquanto que para elaborar a mesma quantidade de queijo, são necessários 6,5 litros de leite bubalino. Sua coloração branca é uma de suas características mais marcantes, devido a ausência do $\beta$-caroteno em sua composição química, o que não é considerado um problema nutricional, uma vez que o leite de búfala possui a vitamina A $(170,22 \mathrm{mg})[9,10,11]$.

Como o Queijo do Marajó é um produto obtido da fermentação espontânea do leite de búfala, e por não possuir nenhum tipo de tratamento térmico, este processo propicia a multiplicação de diversos tipos de micro-organismos, entre eles bactérias lácticas, microorganismos deterioradores e/ou patogênicos, que podem estar presentes no leite ou provenientes da ausência de Boas Práticas de higiene durante a ordenha e/ou fabricação, sendo este um dos problemas de maior relevância nas queijarias da Ilha do Marajó [7, 12, 13]. 
No entanto, em 2013, considerando a importância socioeconômica do Queijo do Marajó para o Pará, a importância de se estabelecer normas higiênico-sanitárias e Boas Práticas de Produção e de Fabricação, suas características históricas e culturais do Marajó, bem como a necessidade de caracterizar seu processo de produção, a Agência Estadual de Defesa Agropecuária do Estado do Pará - ADEPARÁ, através da Portaria $n^{\circ} 418$, de 04/03/2013, aprovou o Regulamento Técnico de Produção do Queijo do Marajó [3]. É importante que todas as queijarias locais estejam de acordo com o recomendado pela Portaria vigente, em virtude da grande aceitação deste derivado. Assim, este trabalho tem como objetivo avaliar a qualidade microbiológica do Queijo do Marajó, tipo creme, de leite de búfala, produzido em duas queijarias que seguem este Regulamento Técnico, a fim de comprovar se os derivados encontram-se em condições microbiológicas e higiênico-sanitárias adequadas, na Ilha do Marajó, Pará.

\section{MATERIAL E MÉTODOS}

O presente trabalho foi realizado com amostras de Queijo do Marajó, tipo creme, de leite de búfala, coletadas em duas queijarias (codificadas como Queijaria A e Queijaria B) localizadas em Soure, na Ilha do Marajó, que elaboram este derivado. Em cada queijaria, foram coletadas duas amostras do produto.

As amostras foram coletadas logo após a sua elaboração, e em seguida, colocadas em caixas isotérmicas, sob temperatura média de $8{ }^{\circ} \mathrm{C}$, e enviadas ao Laboratório de Microbiologia, do Campus XIX de Salvaterra, da Universidade do Estado do Pará - UEPA.

Todas as análises microbiológicas foram realizadas no dia subsequente à elaboração dos produtos. As análises microbiológicas foram: Coliformes Totais, Coliformes Termotolerantes, Staphylococcus aureus, contagem padrão de bactérias aeróbias mesófilas, e contagem de fungos filamentosos e leveduras. As determinações microbiológicas foram realizadas em triplicatas e seguindo os métodos oficiais descritas pelo Ministério da Agricultura, Pecuária e Abastecimento - MAPA [14].

A determinação de Coliformes Totais e Coliformes Termotolerantes foi realizada pela técnica do Números mais Prováveis - NMP com a série de três tubos múltiplos $\left(10^{-1}, 1\right.$ e 10$)$, em tubos de ensaio e tubos de Durhan. Empregou-se, como meio presuntivo, o Caldo Lauril Sulfato Triptose, com um volume de $8 \mathrm{~mL}$ em cada tubo, seguido da incubação em estufa bacteriológica, sob temperatura de $35{ }^{\circ} \mathrm{C}$, por $24-48$ horas. Após leitura, os tubos positivos foram repicados, com auxilio de alça de platina, para Caldo Verde Brilhante bile, a $2 \%$ de lactose, com incubação em estufa bacteriológica, a $35^{\circ} \mathrm{C}$, por $24-48$ horas para confirmação da presença de Coliformes Totais, e repicados para Caldo E.C., com incubação em banho maria, sob temperatura de $44{ }^{\circ} \mathrm{C}$, por $24-48$ horas, visando a confirmação de Coliformes Termotolerantes. A detecção de Staphylococcus aureus foi realizada pela técnica de Petrifilm especifico para esta bactéria, com incubação em estufa bacteriológica, sob temperatura de $35^{\circ} \mathrm{C}$, por 24-48 horas. Para a contagem padrão de bactérias aeróbias mesófilas, utilizou-se o Ágar para contagem em placas - PCA, empregando-se a técnica de cultivo em profundidade, e incubação a $35{ }^{\circ} \mathrm{C}$ por $24-48$ horas. E para a contagem de fungos filamentosos e leveduras, utilizou-se o Ágar Potato Dextrose, sob incubação em estufa B.O.D, a $22^{\circ} \mathrm{C}$ por 4 a 5 dias.

\section{RESULTADOS E DISCUSSÃO}

Os resultados das médias das análises microbiológicas das amostras de Queijo do Marajó, tipo creme, de leite de búfala, das duas queijarias avaliadas, estão apresentados na Tabela 1. 
Tabela 1: Média dos resultados das análises microbiológicas das amostras de Queijo do Marajó, tipo creme, de leite de búfala

\begin{tabular}{|c|c|c|c|}
\hline \multirow{2}{*}{ Determinações microbiológicas } & \multicolumn{2}{|c|}{ Queijarias } & \multirow[t]{2}{*}{ Pará (2013) } \\
\hline & $\mathbf{A}$ & B & \\
\hline Coliformes Termotolerantes (NMP/g) & $<3$ & $<3$ & $<3$ \\
\hline Coliformes Totais (NMP/g) & $<3$ & $<3$ & --- \\
\hline Staphylococcus aureus (UFC/g) & $<1,0 \times 10^{1}$ & $<1,0 \times 10^{1}$ & --- \\
\hline Bactérias aeróbias mesófilas (UFC/g) & $<1,0 \times 10^{1}$ & $<1,0 \times 10^{1}$ & --- \\
\hline Fungos filamentosos e leveduras (UFC/g) & $<1,0 \times 10^{1}$ & $<1,0 \times 10^{1}$ & --- \\
\hline
\end{tabular}

Como pode ser observado na Tabela 1, os produtos elaborados nas duas queijarias, não apresentaram contaminação por nenhum dos micro-organismos analisados, o que comprova que a elaboração do derivado obedeceu os requisitos exigidos pelo Programa de Qualidade, Boas Práticas de Fabricação - BPF, tais como utilização de higiene pessoal, ambiental e de produção do alimento, estando assim de acordo com Portaria $n^{\circ} 418$, de 04/03/2013, do Regulamento Técnico de Produção do Queijo do Marajó [3].

Lourenço (2002) [15], Toro e Souza (2002) [16], Gouvêa e Dias (2004) [8] e Figueiredo (2006) [4] também não detectaram a contaminação por Coliformes Termotolerantes e Totais em nenhuma amostra de Queijo do Marajó avaliada. Somente Bendelak (2004) [12], observou a presença de coliformes totais e termotolerantes, com níveis de $110 \mathrm{NMP} / \mathrm{g}$. Lourenço (2002) [15], Gouvêa e Dias (2004) [8], Bendelak (2004) [12] e Simões et al. (2014) [5] também não detectaram a presença de Staphylococcus aureus ao avaliar a qualidade microbiológica desse derivado.

De acordo com Vieira et al. (2005) [17] o produto passa por vários tipos de aquecimentos durante sua fabricação, iniciando com temperaturas de $55^{\circ} \mathrm{C}$ durante a lavagem e aquecimento da massa e, finalizando com temperaturas de $80{ }^{\circ} \mathrm{C}$ para o cozimento da massa. E a utilização dessas temperaturas também pode contribuir para a ausência de micro-organismos após o processamento no Queijo do Marajó.

$\mathrm{Na}$ avaliação da vida de prateleira do derivado durante 15 dias de armazenamento, sob temperatura de $10{ }^{\circ} \mathrm{C}$, Lourenço et al. (2002) [15] verificaram que os resultados para coliformes totais aumentaram de $3 \mathrm{NMP} / \mathrm{g}$ para $240 \mathrm{NMP} / \mathrm{g}$, e coliformes termotolerantes aumentaram de < $3 \mathrm{NMP} / \mathrm{g}$ para $240 \mathrm{NMP} / \mathrm{g}$, tornando-se inadequado ao consumo humano a partir do $15^{\circ}$ dia. Figueiredo (2006) [4], ao elaborar o mesmo produto com Boas Práticas de Higiene observou que o mesmo só se tornou inadequado ao consumo humano, a partir do $21^{\circ}$ dia, com a multiplicação de fungos filamentosos e leveduras $\left(6,4 \times 10^{3} \mathrm{UFC} / \mathrm{g}\right)$.

Contrapondo os resultados obtidos neste trabalho, muitos autores observaram a contaminação por bactérias aeróbias mesófilas, com níveis de $1,4 \times 10^{2} \mathrm{UFC} / \mathrm{g}$ [8] a 2,0 x $10^{2}$ UFC/g [4] e por fungos filamentosos e leveduras, com valores variando de $1,2 \times 10^{2} \mathrm{UFC} / \mathrm{g}$ [4] a $7,9 \times 10^{5} \mathrm{UFC} / \mathrm{g}$ [15]. De acordo com Guerra e Guerra (2003) [18], das alterações microbiológicas, a presença de fungos filamentosos e leveduras é referida como uma das principais geradoras de problemas na indústria queijeira. Entre os danos causados pelo seu desenvolvimento, destacam-se a alteração da aparência, perda e/ou modificação de sabor, além de queda na credibilidade do produto frente ao mercado consumidor.

A utilização do sorbato de potássio, substância química com propriedades antimicrobianas, com uso indicado para queijos, é uma alternativa para melhorar a qualidade e aumentar a vida útil do produto [19], como foi reportado por Guerra e Guerra (2003) [18] e Figueiredo (2006) [4] ao avaliar Queijos do Marajó elaborados com sorbato de potássio a 0,1\%, verificando que os derivados apresentaram-se adequados ao consumo, além de satisfatório controle de fungos filamentosos e leveduras. O sorbato de potássio pode ser usado na proporção permitida pela legislação vigente (máximo de $0,1 \%$ do peso do produto final) [3]. 


\section{CONCLUSÃO}

Os resultados microbiológicos nas amostras de Queijo do Marajó obtidas de duas queijarias localizadas na Ilha do Marajó mostram que os produtos não apresentaram contaminação microbiológica por nenhum dos micro-organismos analisados, encontrando-se assim de acordo com as exigências da Portaria $n^{\circ} 418$, de 04/03/2013, do Regulamento Técnico de Produção do Queijo do Marajó.

As queijarias avaliadas, além da certificação e da legalização de comercializar o produto, oferecem aos consumidores derivados que possuem qualidade microbiológica, livre de microorganismos deterioradores e/ou patogênicos.

\section{REFERÊNCIAS BIBLIOGRÁFICAS}

1. Pinto MS, Ferreira CLLF, Martins JM, Teodoro VAM, Pires ACS, Fontes LB, Vargas PIR. Segurança alimentar do queijo minas artesanal do serro, Minas Gerais, em função da adoção de Boas Práticas de Fabricação. Pesquisa Agropecuária Tropical. 2009 out;39(4):112-6.

2. Nóbrega JE. Biodiversidade microbiana, descritores físico-químicos e sensoriais dos queijos artesanais fabricados nas regiões da Serra da Canastra e do Serro, Minas Gerais [tese]. Universidade Federal de Viçosa; 2012. 121p.

3. Pará, 2013. Agência Estadual de Defesa Agropecuária do Estado do Pará - ADEPARÁ. Aprova o Regulamento Técnico para a Produção do Queijo do Marajó. Portaria No 418 de 04/03/2013 (Estadual - Pará).

4. Figueiredo EL. Elaboração e caracterização do Queijo do Marajó tipo creme, de leite de búfala, visando sua padronização [dissertação]. Mestrado em Ciência Animal - Produção Animal. Universidade Federal do Pará; 2006. 180p.

5. Simões MG, Portal RE, Rabelo JG, Ferreira CLLF. Seasonal variations affect the physicochemical composition of bufallo milk and artisanal cheeses produced in Marajó Island (PA, Brazil). Advance Journal of Food Science and Technology. 2014. p.81-91.

6. Bittencourt RHFPM. Requeijão Marajoara e Queijo Minas Frescal Produzidos com Leite de Búfalas (Bubalus Bubalis, lin.) no Estado do Pará [dissertação]. Mestrado em Higiene Veterinária e Processamento Tecnológico de Produtos de Origem Animal. Universidade Federal de Fluminense, 2011. 106p.

7. Figueiredo EL, Lourenço Júnior JB, Toro MJU, Lima SCG. Queijo do Marajó tipo creme: parâmetros físico-químicos e sensoriais. Revista Instituto Laticínios Cândido Tostes. 2011. 378(66);26-33.

8. Gouvêa CAL, Dias JDC. Caracterização do Queijo do Marajó e levantamento do pessoal envolvido no processo para orientação e inserção social [monografia]. Universidade do Estado do Pará. 2004. 69p.

9. Macedo MP, Wechsler FS, Ramos AA, Amaral JB, S JC, Resende FD, Oliveira JV. Composição físico-química e produção de leite de búfalas da raça mediterrâneo no oeste do Estado de São Paulo. Revista Brasileira de Zootecnia (suplemento). 2001. 30(3);1084-1088.

10. Teixeira LV, Bastianetto E, Oliveira DAA. Leite de búfala na indústria de produtos lácteos, Revista Brasileira de Reprodução Animal. 2005. abri. 29(2);96-100.

11. Andrade KV, Rangel AHN, Araújo VM, Lima Júnior DM, Oliveira NA. Efeito da estação do ano na qualidade do leite de búfalas. RVADS. 2011. 6(3);33-37.

12. Bendelak MR. Processo produtivo, características físico-químicas e microbiológicas e sugestão de implantação do Sistema de Análise de Perigos e Pontos Críticos de Controle na produção do queijo marajoara tipo crème [dissertação]. 2004. Mestrado em Ciência Animal. Centro Agropecuário. Universidade Federal do Pará.

13. Bittencourt RHFPM, Cortez MAS, Mársico ET, Rosa RMSS, Taxi CMADC, Ermita PAN. Caracterização de Requeijão Marajoara e Minas Frescal produzidos com leite de búfalas no Estado do Pará, Brasil. Ciência Rural, Santa Maria. 2013. Set(43)9;1687-1692.

14. Brasil. Ministério da Agricultura, Pecuária e Abastecimento. Análises microbiológicas para controle de produção de origem animal e água: Instrução normativa $n^{\circ}$ 62. Brasília: MAPA, 2003.

15. Lourenço LFH, Simão Neto M, Lourenço Júnior JB. Análise microbiológica do requeijão marajoara elaborado no norte do Brasil. Revista Higiene Alimentar. São Paulo. 2002. (16)94;55-59.

16. Toro MJU, Souza CL. Microbiologic and phisical-chemical characteristics of cheese "Marajoara" sold in Belem, Para State, Brazil. In: Buffalo Symposium of Américas. 2002, Belém. 591-593.

17. Vieira LC, Lourenço Júnior JB, Alves OS, Monteiro EMM, Santos NFA. Produção de requeijão Marajoara de leite de búfala. ZOOTEC. 2005. maio. Anais..., Campo Grande-MS. 
18. Guerra TMM, Guerra NB. Influência do Sorbato de Potássio e do Tipo de Embalagem Sobre a Vida Útil do Queijo de Manteiga (Requeijão do Norte). Brazilian Journal of Food Technology. 2003. $\operatorname{Jul}(6) 2 ; 259-265$.

19. Brasil. Ministério da Agricultura, Pecuária e Abastecimento. Secretaria de Defesa Agropecuária. Departamento de Inspeção de Produtos de Origem Animal. Regulamentos Técnicos de Identidade e Qualidade de Leite e Produtos Lácteos. Portaria $\mathrm{n}^{\circ}$ 359. Regulamento técnico para fixação de identidade e qualidade do requeijão cremoso ou requesón. Brasília, DF, 1997. 